\title{
Water Tank and Wind Tunnel Tests on Rain Gauge Wind Shield
}

\author{
by \\ M. Sanuki, N. Tsuda and S. Kimura \\ Meteorological Research Institute \\ (Received January 7, 1952)
}

\begin{abstract}
Two types of wind shield for rain gauge, i. e., conical and hollow ring-shaped designs are tested in combination with integral and separated equipment housings, both in water tank and in wind tunnel. The flow patterns are photographed by means of aluminium powder spread over the water surface of the tank, or wool strings tied to the model in the wind tunnel. By the inspection of the photographs taken in two-dimensional aspect in water tank, together with those taken in three-dimensional aspect in wind tunnel, the conical wind shield with a flat circular edge combined with separated housing is found to be the most satisfactory, giving uniform horizontal flow and generating the minimum of eddies around the rain gauge funnel mouth.
\end{abstract}

\section{Object of the test}

For automatic weather station or remote rain gauge, the construction of which is now in progress in our Institute, a proper wind shield seems to be indispensable to avoid undesirable air-flow disturbance caused by surrounding obstacles. In Japan rain gauges have hither to been used without any wind shield, owing to the lack of experimental basis to be trusted upon. The present test was first carried out in the $85 \mathrm{~cm}$ water tank of the Institute [1], to determine the size, form and arrangement of the wind shield. The conclusions obtained from the tank test are valid for two-dimensional cases only. For three-dimensional confirmation, the wind tunnel test was resorted to for the models selected from the tank test.

The tasks imposed upon the rain gauge wind shield in general are as follows:

i) horizontal rectilinear flow over the rain gauge funnel,

ii) minimum acceleration of the said flow, and

iii) minimum generation of eddies at all parts of the flow. 


\section{Description of water tank models}

Two forms of wind shield model, i. e., conical and ring-formed, are tested in the water tank. Their dimensions are illustrated in Figs. 1 and 2. The scale of model is $1 / 5$ of actual equipment. The material is $1 \mathrm{~mm}$ thick aluminium sheet. The models have $200 \mathrm{~mm}$ depth and rest on the immersed deck hung under the towing carriage.

The wind shield is combined with two housing types of collecting and recording apparatus, i. e., integral type (actually adopted at present in Japan) and separated type*. The distance of separation of the latter type is changed in two ways, i. e., $0.75 d$ and $2.25 d$, where $d=40 \mathrm{~mm}$ (200 $\mathrm{mm}$ in full scale) is the funnel diameter. The outside diameter of the conical wind shield is changed in four ways, i. e., $4.6 d, 5.5 d 6.5 \mathrm{~d}$, and $7.5 d$ where $4.6 d$ corresponds to the case of no clearance between the funnel side wall and the shield cone. The outside diameter of the ring-formed wind shield are the same except the case of no clearance for which it is $3.5 d$.

The distance of the collecting and recording housing bottom from the side plate hung under the towing carriage which represents the ground ${ }^{* *}$, is kept at a constant value of $4.35 d$ for both integral and separated housings. The effect of the other tank side wall is con

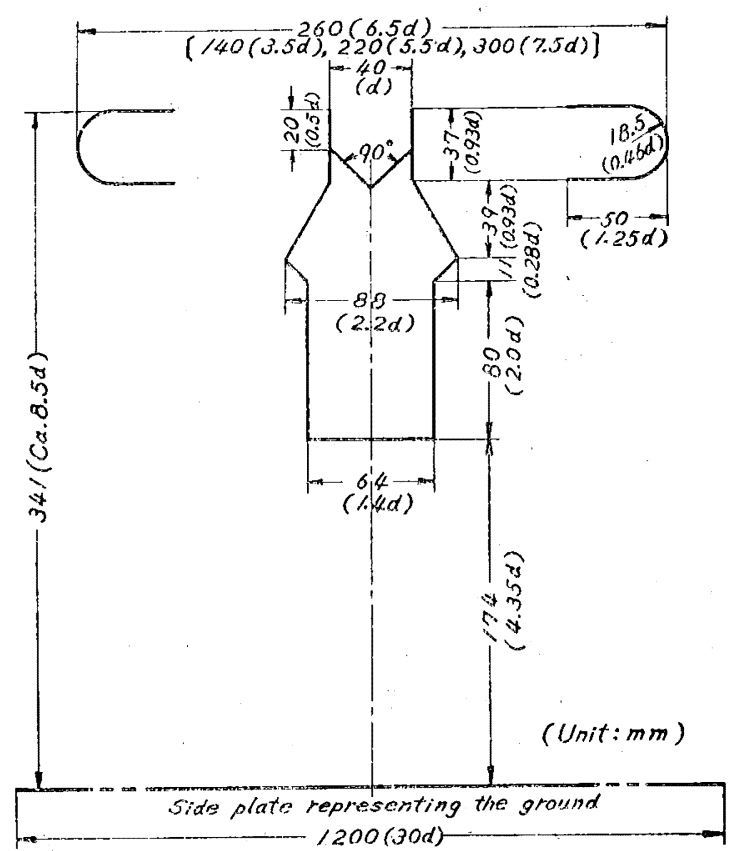

Fig. 1. 1/5 scale model of integral housing combined with ring-formed wind shield for water tank.

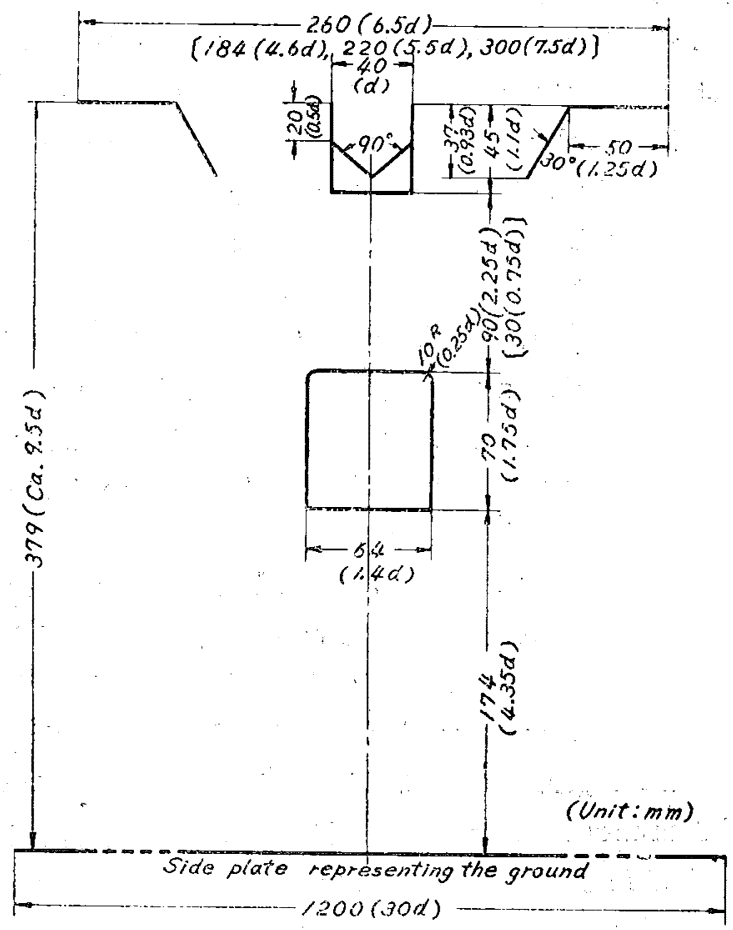

Fig. 2. $1 / 5$ scale model of separated housing combined with conical wind shield for water tank.

* The separated distance is to be connected with a single duct pipe in actual case.

** The housing is to he sunnorted on a auadrapod on the ground in actual case. 
sidered to be negligible as the upper surface of the wind shield travels nearly along the center line of tank channel.

The towing speed is within the range of $5 \sim 15 \mathrm{~cm} / \mathrm{s}$ and the corresponding Reynolds number is $1.7 \sim 5.0 \times 10^{3}$ with respect to the funnel diameter. The actual Reynolds number for the funnel diameter of $200 \mathrm{~mm}$ is $6.8 \times 10^{4}$ at an air speed of $5 \mathrm{~m} / \mathrm{s}$.

The total number of model combinations is 23 including no wind- shield cases, and each combination is tested at three towing speeds of 5,10 and $15 \mathrm{~cm} / \mathrm{s}$. Moreover the flow pattern is non-stationary and every snapshot is made several times to catch different flow development. The illustrations cited below show only a part of the test results, but represent typical flows around each combination.

\section{Description of the tank test results}

\section{i) Flow around integral housing alone}

In Fig. 3 is shown the flow around the integral housing alone. Interse upward torrent is observed around the funnel windward edge (always the left direction in the following tank photographs) which may cause enormous error in precipitation observation. This torrent is undoubtedly generated by the slope of the housing side wall.

If the funnel bottom is separated from the housing at a distance of $0.75 d$ from the flat housing roof, the upward flow is markedly diminished (Fig. 4), but not yet satisfactory as the streamlines over the funnel are still curved and dense.

\section{ii) Folw around integral housing with conical wind shield}

In Fig. 5 is shown the flow around the integral housing with conical wind shield of diameter $4.6 \mathrm{~d}$. The streamlines over the wind shield are remarkably improved but a vortex is being generated at the windward edge. As the wind shield outside diameter increases, the current is let in through the wind shield bottom clearance and a violent jet stream blows up the streamlines (Fig. 6). The jet stream becomes milder as the diameter further increases, and then approaches to the state of housing alone. Thus the installation of the wind shield has rather adverse effect in this case.

iii) Flow around integral housing with ring-formed wind shield

This arrangement, as can be seen from Fig. 7, shows no improvement compared with the case of housing alone for all wind shield diameters.

\section{iv) Flow around separated housing with conical wind shield}

This arrangement with a larger separation distance $2.25 d$ gives the best of all the present test results. Especially the outside diameter of $6.5 d$ gives the most desirable features, i. e., straight, horizontal and uniform streamlines and minimum eddy formation (Fig. 8). The outside diameter of $5.5 d$ has nearly the same merit (Fig. 9) and that of $7.5 d$ a little inferior (Fig. 10). 
The arrangement with smaller separation distance $0.75 d$ is good but at times the eddy is emitted upward from the windward clearance between the wind shield and the funnel.

v) Flow around separated housing with ring-formed wind shield

This arrangement with a larger separation distance $2.25 d$ is fairly well . (Fig. 11), but eddies generated between the spaces between the wind shield and the funnel (Fig. 12) are apt to come out to the funnel mouth.

The arrangement with a smaller separation distance $0.75 d$ causes upward flow over the funnel and is not desirable.

On the whole, separated housing with a separation distance $2.25 d$ and equipped with the conical wind shield of from $5.5 \mathrm{~d}$ to $6.5 d$ in its outside diameter, promises the most satisfactory performance. The water tank test is a two-dimensional treatment. Three-dimensional discussion of the foregoing conclusions is transferred to the following wind tunnel test.

\section{Description of wind tunnel models}

The wind tunnel model is prepared in accordance with Fig. 2 with the funnel diameter $d=100 \mathrm{~mm}$, i. e. in half-size of the actual equipment. The wind shield outside diameter of $650 \mathrm{~mm}(6.5 d)$ is selected as the best compromise according to the tank test. Other dimensions are exactly the same as those illustrated in Fig. 2, except an 1-inch diameter pipe connecting the funnel and separated housing below, and minor rigs supporting the wind shield. The separated housing rests on four wooden legs to keep the distance of $4.35 d$ above the floor which represents the ground.

The model is tested in four combinations:

i) Separated cylindrical housing combined with conical wind shield with flat circular edge, i. e., the three-dimensional representation of the water tank model illustrated in Fig. 2.

ii) Ditto, but with 24 holes of diameter $30 \mathrm{~mm}(0.3 d)$ in two rows on the conical surface of the wind shield.

iii) Ditto, but without circular edge and holes on the conical surface.

iv) Ditto without circular edge, but with holes on the conical surface.

The flat circular edge is examined, after the tank test is conducted, of its tendency to keep the fallen snow with the probable result of air flow disturbance, and the wind tunnel test is carried out also without it.

The conical surface of wind shield are bored in order to obtain the probable flow equalizing effect. The holes are labeled with pieces of white paper for the test without them.

The whole set-up is placed in the measurement space of $1.5 \mathrm{~m}$ : wind tunnel of Meteorological Research Institute: The top clearance in the tunnel flow is about $450 \mathrm{~mm}$ and the floor is fixed at about $150 \mathrm{~mm}$ above the lower margin of the flow. 
The air speed at which the test is conducted ranges from 1.5 to $20 \mathrm{~m} / \mathrm{s}$, the corresponding Reynolds number being $1.0 \sim 14 \times 10^{4}$ with respect to the rain gauge funnel diameter. The flow around the funnel and wind shield is visualized by means of short, black and white wool strings tied to the main positions of the model. Further, air speed measurement is done at a position of $50 \mathrm{~mm}(0.5 d)$ above the funnel mouth. The photographs are taken for every model combination and every tunnel speed with a fixed shutter speed of $1 / 100 \mathrm{sec}$.

\section{Description of wind tunnel test results}

i) The separated housing combined with the wind shield with a circular edge gives the desired flow features, i. e., horizontal flow over the funnel mouth and minimum generation of eddies even at high air speed (Fig. 13). The air speed at a height of $50 \mathrm{~mm}(0.5 \mathrm{~d})$ above the funnel mouth is nearly equal to the tunnel flow speed. The air speed is only 2 to $3 \%$ more or less than the general flow and perfectly steady.

ii) The existence of the holes on the conical surface of the wind shield seems to stabilize the flow inside the wind shield cone. The flow pattern and the air speed magnitude above the funnel mouth remain unchanged in presence of these holes (Fig. 14).

iii) If the circular edge, however, is removed, the flow inside the wind shield cone and also above the funnel mouth becomes utterly turbulent (Fig. 15), even though it is somewhat tempered by the existence of holes perforated on the wind shield conical surface (Fig. 16). The air speed above the funnel mouth is some $10 \%$ lower than the tunnel flow speed and hard to measure owing to its intense fluctuation in both cases.

Thus the flat circular edge of the wind shield is indispensable to obtain stable flow over the funnel. To avoid the accumulation of fallen snow on the circular edge, perforations should be provided, which apparently have no detrimental effect to the flow, though not tested in the present experiment.

iv) As the last experiment the three-dimensional model of integral housing is tested. The scale of the model is $1 / 2$ of the actual equipment. The results are illustrated in Fig. $17 \mathrm{a}$ (side view) and Fig. $17 \mathrm{~b}$ (plan view), from which intense upwash and turbulence of local stream are observed. The measurement of wind speed over the funnel at a height of the funnel radius gives ca. $85 \%$ of the tunnel flow with excess fluctuations. Thus the conclusions drawn from the tank tests are confirmed also in the wind tunnel.

\section{Conclusions}

1) Integral rain gauge housing now actually used in Japan is inadequate to obtain undisturbed flow around the funnel. No wind shield of any form seems to 
Flow $\rightarrow$

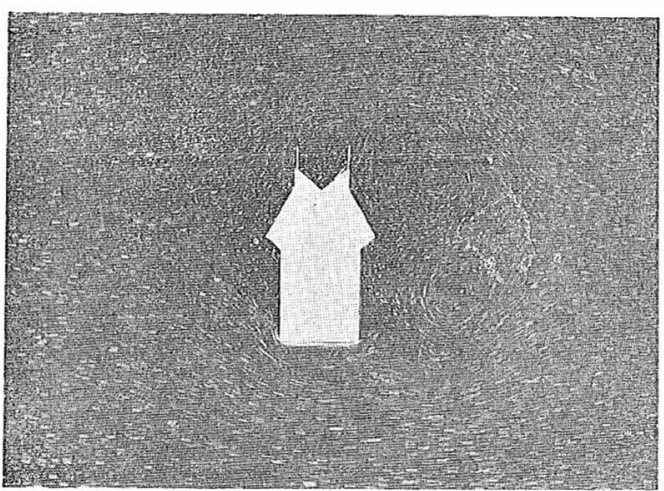

Fig. 3. Integral housing alone. Towing speed $V=5 \mathrm{~cm} / \mathrm{s}$. (M.R.I. Water tank, flow from the left).

Flow $\rightarrow$

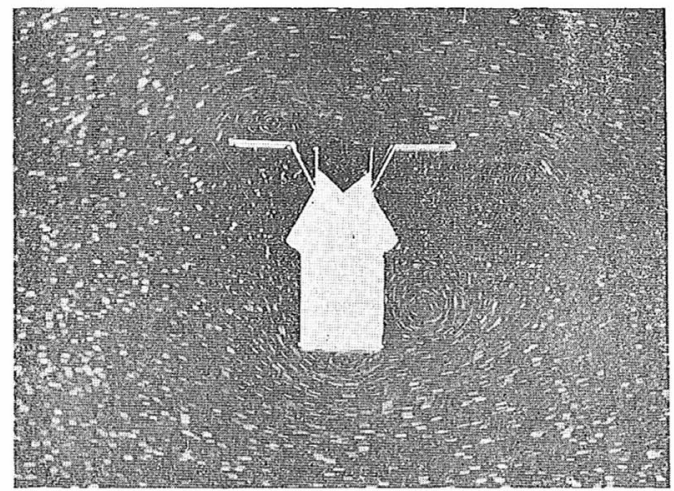

Fig, 5. Integral housing with conical wind shield of outside diameter $4.6 \mathrm{~d}$. $V=$ $5 \mathrm{~cm} / \mathrm{s}$. (M.R.I. water tank).

\section{Flow $\rightarrow$}

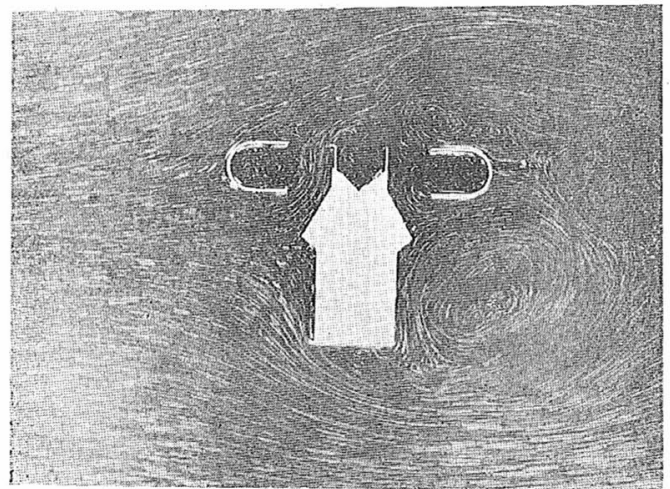

Fig. 7. Integral housing with ring-formed wind shield of outside diameter $5.5 \mathrm{~d}$. $V=15 \mathrm{~cm} / \mathrm{s}$. (M.R.I. water tank),
Flow $\rightarrow$

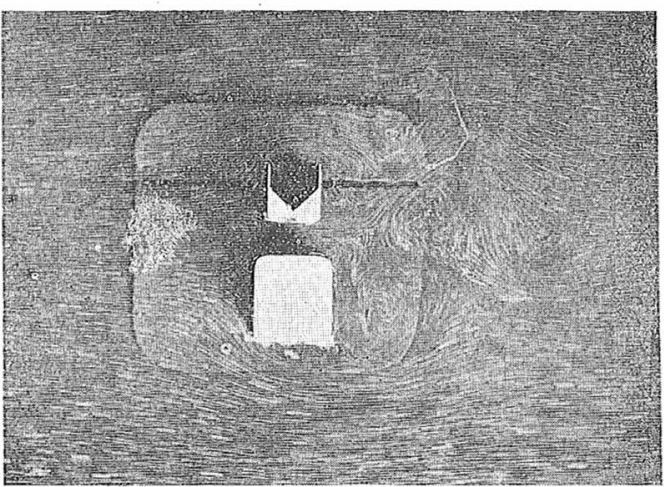

Fig. 4. $0.75 d$ separated housing alone. $V=$ $10 \mathrm{~cm} / \mathrm{s}$. (M.R.I. water tank).

Flow $\rightarrow$

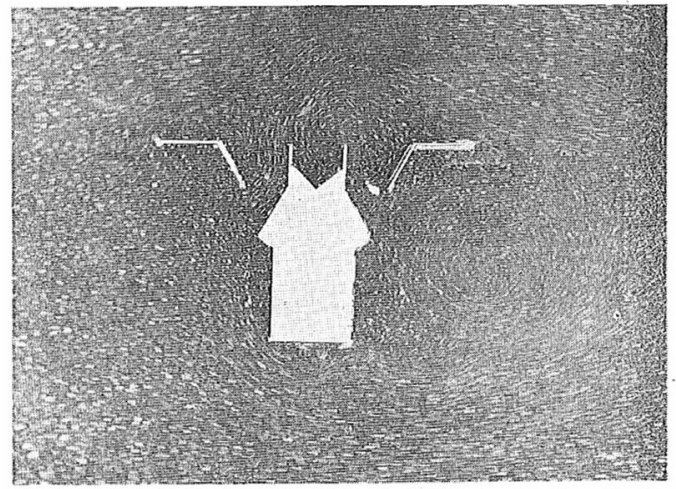

Fig. 6. Integral housing with conical wind shield of outside diameter $6.5 d . V=5 \mathrm{~cm} / \mathrm{s}$. (M.R.I. water tank).

Flow $\rightarrow$

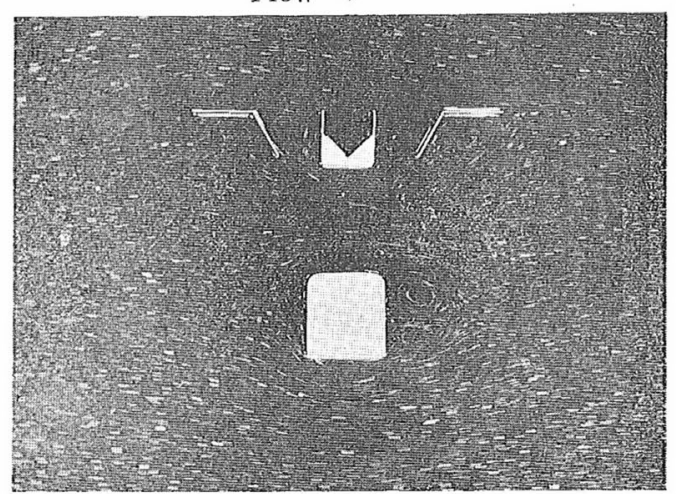

Fig. 8. $2.25 d$ separated housing with conical wind shield of outside diameter $6.5 d . V=$ $5 \mathrm{~cm} / \mathrm{s}$. (M.R.I. water tank). 
Flow $\rightarrow$

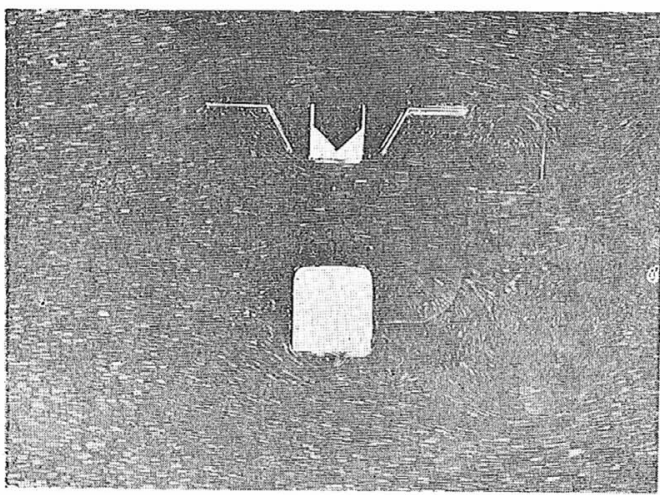

Fig. 9. $2.25 d$ separated housing with conical wind shield of outside diameter $5.5 \mathrm{~d} . \mathrm{V}$ $=5 \mathrm{~cm} / \mathrm{s}$. (M.R.I. water $\tan \mathrm{k}$ ).

Flow $\rightarrow$

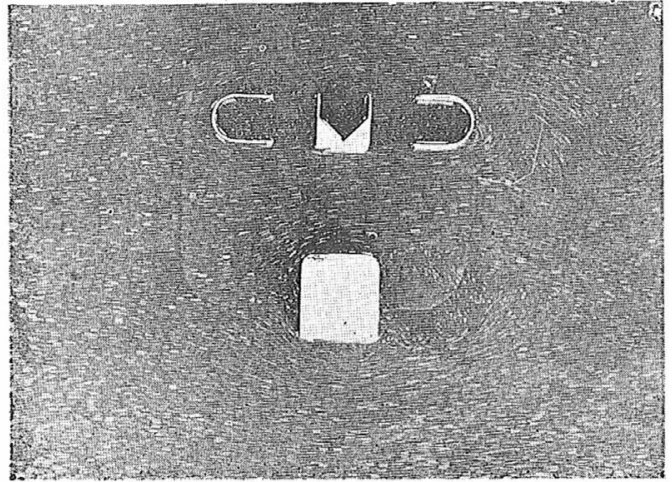

Fig. 11. $2.25 d$ separated housing with ringformed wind shield of outside diameter $5.5 \mathrm{~d}$. $V=5 \mathrm{~cm} / \mathrm{s}$. (M.R.I. water tank).
Flow $\rightarrow$

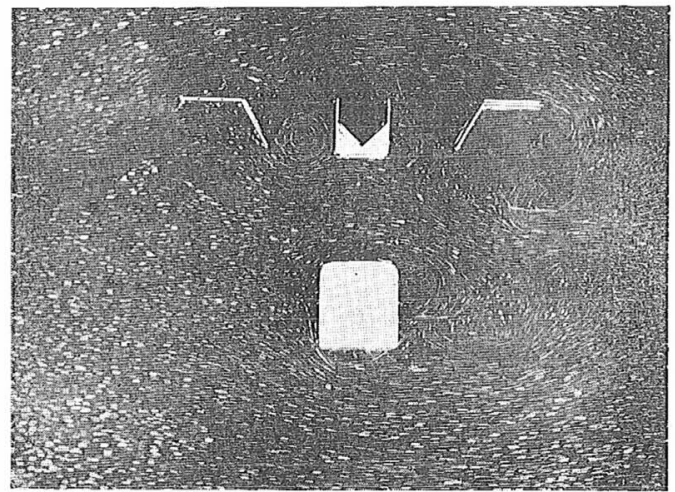

Fig. 10. $2.25 d$ separated housing with conical wind shield of outside diameter $7.5 \mathrm{~d} . V=$ $4 \mathrm{~cm} / \mathrm{s}$. (M.R.I. water tank).

Flow $\rightarrow$

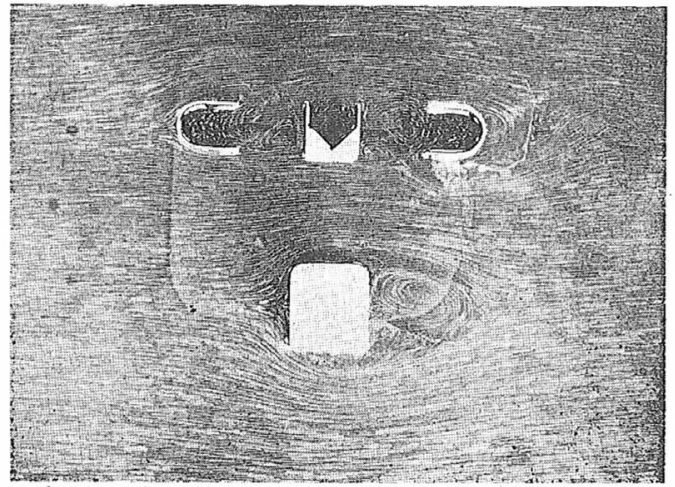

Fig. 12. 2.25d separated housing with ring. 15 formed wind shield of outside diameter 6.5 d. $V=15 \mathrm{~cm} / \mathrm{s}$. (M.R.I. water tank). 


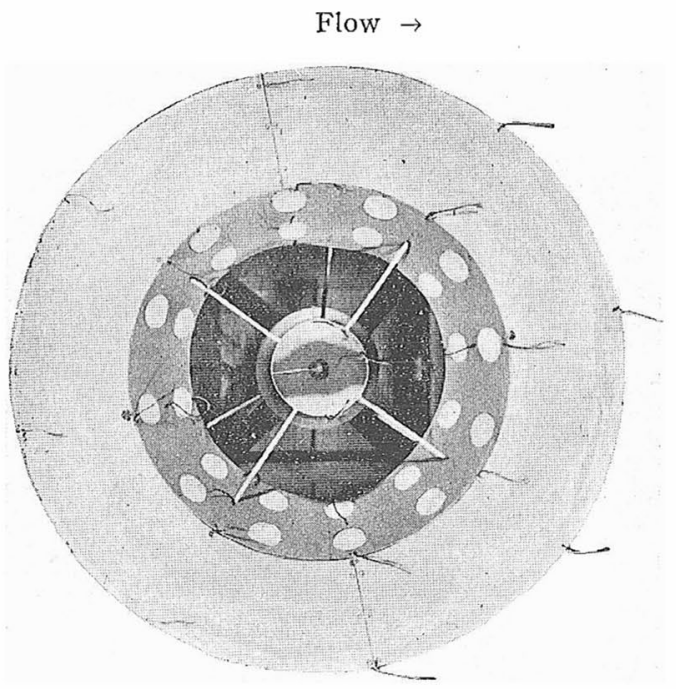

Fig. 13. Separated housing with conical wind shield with circular edge. Wind speed $V=14.5 \mathrm{~m} / \mathrm{s}$. (Plan view, flow from the 1eft, M.R.I. wind tunnel).

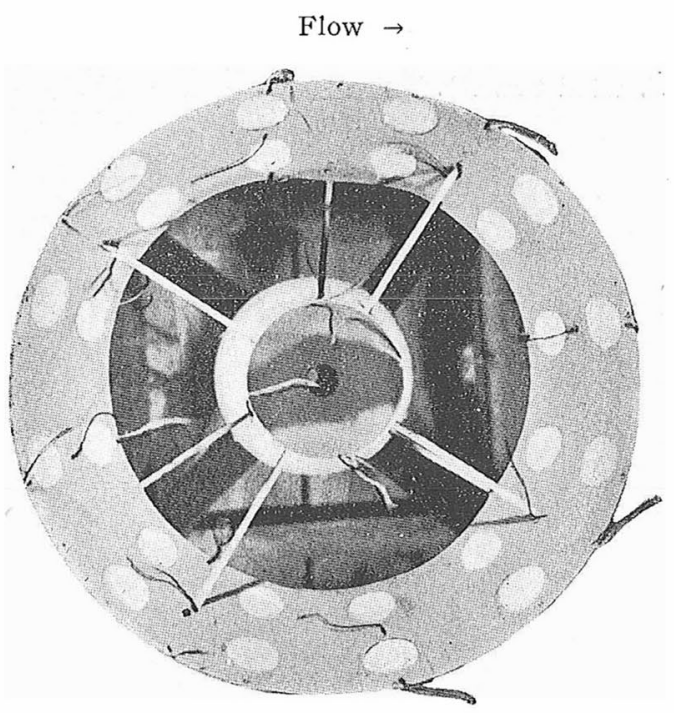

Fig. 15. Separated housing with conical wind shield only. $V=14.4 \mathrm{~m} / \mathrm{s}$. (Plan view, flow from the left, M.R.I. wind tunnel).

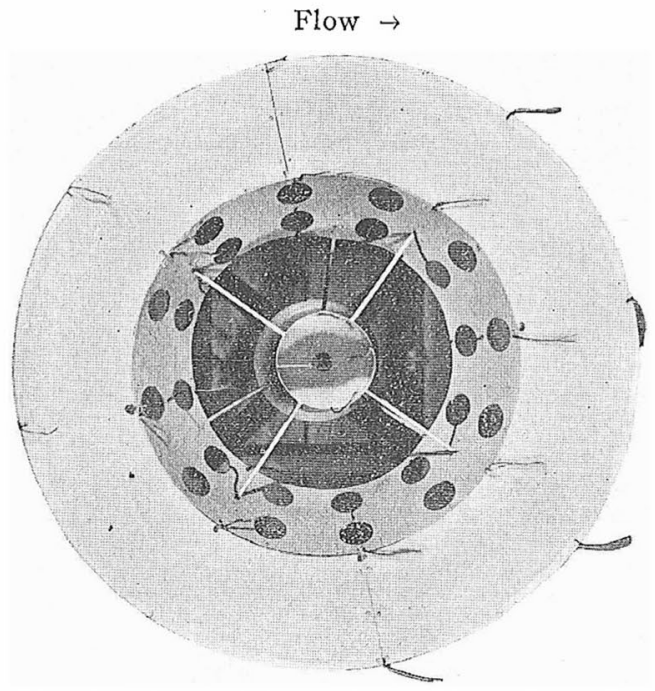

Fig. 14. Separated housing with perforated conical wind shield with circular edge. $V=14.5 \mathrm{~m} / \mathrm{s}$. (Plan view, M.R.I. wind tunnel).

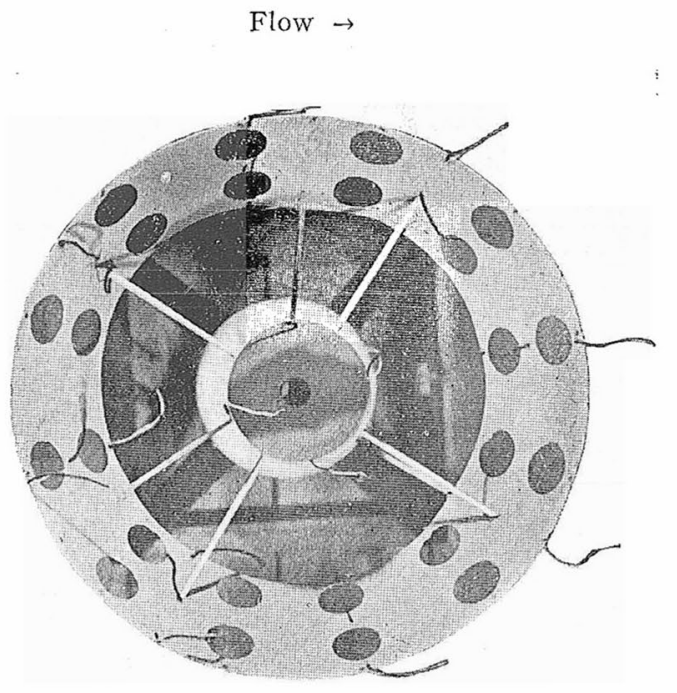

Fig. 16. Separated housing with perforated conical wind shield only. $V=14.5 \mathrm{~m} / \mathrm{s}$. (Plan view, M.R.I. wind tunnel). 

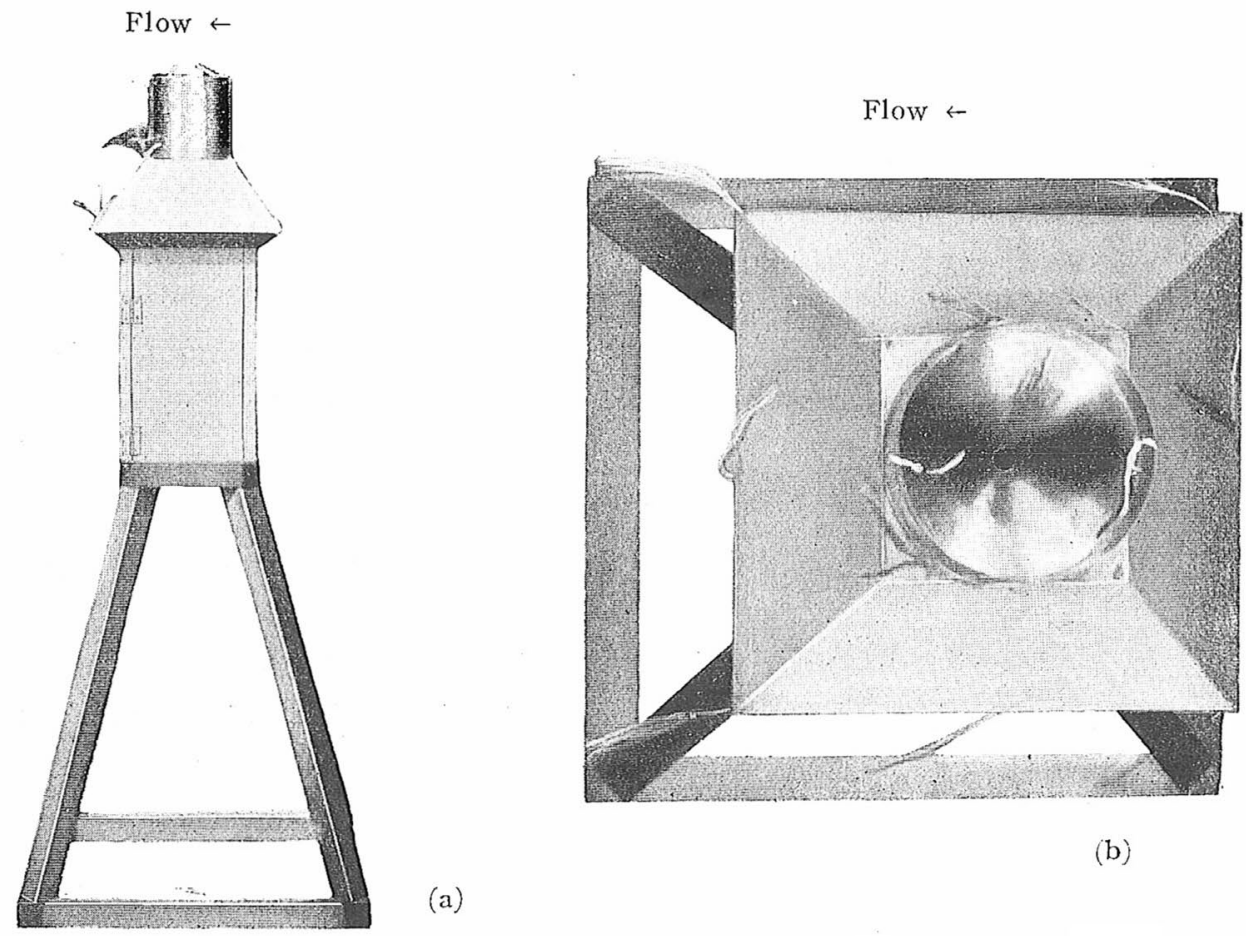

(b)

(a)

Fig. 17. Integral housing alone. $V=15.3 \mathrm{~m} / \mathrm{s}$. (Side and plan view, flow from the right, M.R.I. wind tunnel). 
afford a remedy for it.

2) Separated rain gauge housing with the conical wind shield with a circular edge of outside diameter of 6.5 times the funnel mouth diameter gives the most satisfactory result.

3) Perforations on the conical surface of the wind shield improve the flow pattern.

4) Flat circular edge of the wind shield is indispensable and it should be perforated to avoid the accumulation of the fallen snow on it.

\section{References}

[1] Sanuki, M., Tsuda, N. and Kusano, A. 1951: Tank Test of Radiosonde Ventilator Tubes, Papers in Meteorology and Geophysics, 2, p. 196.

Also the elaborate researches by Prof. Dr. P.L. Mercanton, 1938, should be referred to.

Recherches de technique pluviométrique, Annalen der Schweizerischen Meteorologischen Zentralanstalt. 